\title{
Microstructural, morphological and optical properties of sprayed thin films of indium doped gadolinium oxide $\left(\mathrm{Gd}_{2} \mathrm{O}_{3}: \operatorname{In}\right)$
}

\author{
Zaid Rossi ${ }^{1, *}$, Bilal Brioual ${ }^{1}$, Abdesamad Aouni ${ }^{1}$, Mustapha Diani $^{1}$, and Mohammed Addou ${ }^{1}$ \\ ${ }^{1}$ Equipe de recherche en Couches Minces et Nanomatériaux (CMN), FST, Université Abdelmalek Essâadi, Tanger-Maroc, Morocco
}

\begin{abstract}
This paper featured a study on undoped and Indium doped Gadolinium oxide $\mathrm{Gd}_{2} \mathrm{O}_{3}$ : In thin films, elaborated on a glass substrates at temperature of $500{ }^{\circ} \mathrm{C}$ by homemade Spray Pyrolysis technique, at different Indium concentrations as follow $0,2,4,6$ and 8 at \%. This thin layers, where a subjects to a numerous characterization techniques to study the effect caused by introducing the dopant element "Indium" in Gadolinium oxide lattice on the structural properties (X-Ray Diffraction and Raman spectroscopy) and optical properties. The structural characterization carried by the X-ray diffraction (XRD) reveals a polycrystalline Monoclinic B-type structure for all $\mathrm{Gd}_{2} \mathrm{O}_{3}$ :In thin films. Moreover, these findings are verified by the Raman spectroscopy results. Concerning the optical properties of our thin films, the optical measurements carried by UV-VIS-NIR spectrophotometer shows an increase in the transmittance value within the visible region [370-900 nm] and in the band gap energy value by raising Indium doping rate from 0 at $\%$ to 6 at $\%$, also the disorder caused inside the thin films were estimated by the Urbach equation. That said, the 2 at \% Indium doped gadolinium oxide thin film provides interesting results that can be applied in solar cells as an optical window material.
\end{abstract}

\section{Introduction}

Through the years, the transparent conducting oxides or TCO's were and still used in a variety of domains due to their electrical, optical, structural and morphological properties. The rare earth oxides more precisely Lanthanide oxides belongs to the TCO's family and gadolinium oxide ' $\mathrm{Gd}_{2} \mathrm{O}_{3}$ ' is one of them. The gadolinium oxide has a three-crystal structure variant as follow: Cubic $\left(\mathrm{c}-\mathrm{Gd}_{2} \mathrm{O}_{3}\right)$ [1] Monoclinic $\left(\mathrm{m}-\mathrm{Gd}_{2} \mathrm{O}_{3}\right)$ [2] and finally Hexagonal structure $\left(\mathrm{h}-\mathrm{Gd}_{2} \mathrm{O}_{3}\right)$ that present themselves through a variation of temperature [3] and pressure [4].

Gadolinium oxide is an n-type semiconductor, large band gap, high order of transparency and high dielectric constant allowing him to be used firstly as thin film in optoelectronic devices [5], alternative gate dielectric of $\mathrm{SiO}_{2}$ [6], spectral converter [7]. Secondly as nanoparticles in biomedical domain as a contrast agent for imaging [8] either in its undoped form or by introducing some doping elements to $\mathrm{Gd}_{2} \mathrm{O}_{3}$ matrix such as $\mathrm{Yb}^{3+}[9] \mathrm{Eu}^{3+}[10] \mathrm{Tb}^{3+}$ [11] $\mathrm{Bi}^{3+}[12]$ toward investigating and refining the thin film properties to each desirable applications cited before.

Gadolinium oxide thin films are obtained through a variety of elaboration technics characterize either by their low cost: Sol-Gel method [13], Ultrasonic Spray Pyrolysis [8], Precipitation method [14] or expansive methods such as Molecular Beam Epitaxy [15], Pulsed Laser Deposition [2], Atomic Laser Deposition [16], Radio Frequency magnetron sputtering [17] and Metalorganic Chemical Vapor Deposition method [6].

Herein this study, we exhibit for the first time, to our knowledge, a study of the microstructural and optical properties of the undoped and Indium doped Gadolinium oxide thin films acquired by a Spray Pyrolysis technic.

\section{Experimental method}

\subsection{Material synthesis}

Indium doped Gadolinium oxide, $\mathrm{Gd}_{2} \mathrm{O}_{3}$ : In, thin films were synthesized by a homemade spray pyrolysis technique; a description of the technique was explained in [18]. Using a precursor prepared by dissolving Gadolinium Chloride Hexahydrate $\left(\mathrm{GdCl}_{3}, 6 \mathrm{H}_{2} \mathrm{O}\right.$; purity $99 \%)$ as matrix and Indium chloride $\left(\mathrm{InCl}_{3}\right)$ as Indium dopant source into a $30 \mathrm{ml}$ of distilled water.

Different concentration of Indium were used 0 at, 2 at, 4 at, 6 at and 8 at \% to study the physical properties of the above thin layers.

Each sample was obtained by fixing certain parameters such as, solution concentration of $0,02 \mathrm{M}$, deposition time to $6 \mathrm{~min}$, substrate temperature to $500{ }^{\circ} \mathrm{C}$, spraying rate to $2 \mathrm{ml} / \mathrm{min}$.

Each sample was elaborated by transporting the desirable solution through tube with a flow rate of 2 $\mathrm{ml} / \mathrm{min}$ in order to spray it to fine droplets by the help of a carrier gas presented by air to reach the clean, preheated glass substrates at $500{ }^{\circ} \mathrm{C}$. The deposition parameters are summarized in Table 1.

\footnotetext{
* Corresponding author : zrossi@uae.ac.ma
} 
Table 1. Experimental parameters used for $\mathrm{Gd}_{2-\mathrm{x}} \mathrm{In}_{\mathrm{x}} \mathrm{O}_{3}(\mathrm{x}=0,2$, 4,6 and 8 at \%).

\begin{tabular}{|c|c|}
\hline Deposition parameters & values \\
\hline Precursor source & $\mathrm{GdCl}_{3}, 6 \mathrm{H}_{2} \mathrm{O}$ \\
\hline Concentration & $0,02 \mathrm{M}$ \\
\hline Dopant source & $\mathrm{InCl}_{3}(0,2,4,6$ and 8 at $\%)$ \\
\hline Temperature & $500{ }^{\circ} \mathrm{C}$ \\
\hline Deposition time & $6 \mathrm{~min}$ \\
\hline Nozzle-substrate distance & $40 \mathrm{~cm}$ \\
\hline Flow rate of solution & $2 \mathrm{ml} / \mathrm{min}$ \\
\hline Solution volume & $30 \mathrm{ml}$ \\
\hline Substrate & $\mathrm{Micro} \mathrm{slide} \mathrm{glass}$ \\
\hline
\end{tabular}

\subsection{Materials characterization}

The structural properties of the undoped and doped thin films were investigated by using X-ray diffraction (XRD) system with $\mathrm{Cu} \mathrm{Ka}$ radiation $(1=1.5418 \AA)$, the $\mathrm{X}$-ray generator's power was $1000 \mathrm{~W}(40 \mathrm{kV}, 25 \mathrm{~mA})$, the scan range; from $7.5^{\circ}$ to $70^{\circ}$, the scanning speed was $1 \mathrm{~s} / \mathrm{step}$, where one step corresponds to $0.029^{\circ}$. To reveal the vibrational modes between atoms in the lattice we have used a micro-Raman spectroscopy SENTERRA II, by fixing the source laser emitting at $532 \mathrm{~nm}$. Furthermore, to study the optical properties, we have used SHIMADZU UV-Vis-NIR spectrophotometer, the wave number range was from 220 to $1600 \mathrm{~nm}$.

\section{Results and discussions}

\subsection{X-ray diffraction results}

Figure 1 illustrates the X-ray diffraction (XRD) patterns of undoped and Indium doped Gadolinium oxide $\mathrm{Gd}_{2}$ ${ }_{\mathrm{x}} \mathrm{In}_{\mathrm{x}} \mathrm{O}_{3}(\mathrm{x}=0,2,4,6$ and 8 at $\%)$ thin layers prepared at $500{ }^{\circ} \mathrm{C}$.

The X-ray diffraction patterns in Figure 1 match with the monoclinic B-type structure (Space group $\mathrm{C} 2 / \mathrm{m}$ ) without any secondary phases of the source $\mathrm{Gd}_{2} \mathrm{O}_{3}$ according to Joint Committee on Powder Diffraction Standards ,JCPDS, card number 01-076-7419 nor the Indium, dopant element, such as $\mathrm{In}_{2} \mathrm{O}_{3}$ or some Indium Gadolinium alloys or couponed were detected. Proving that Indium ions were successfully incorporated into lattice sites of gadolinium oxide " $\mathrm{Gd}_{2} \mathrm{O}_{3}$ " and act as dopant.

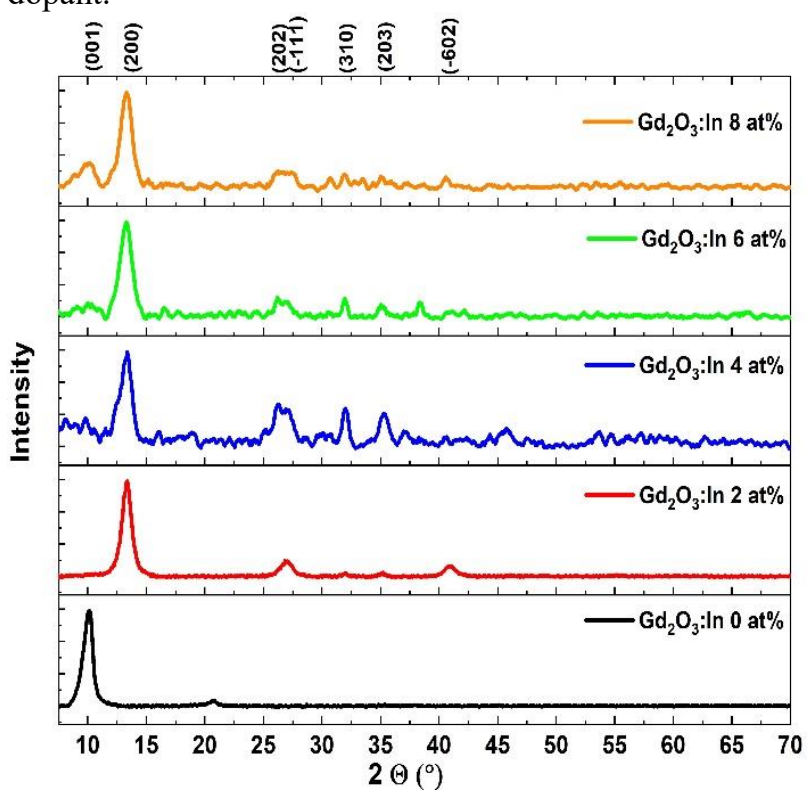

Fig. 1. $\mathrm{X}$-ray diffraction of $\mathrm{Gd}_{2-\mathrm{x}} \mathrm{In}_{\mathrm{x}} \mathrm{O}_{3}(\mathrm{x}=0,2,4,6,8$ at $\%)$ thin layers deposited on glass substrates.

As can be seen, all films in Figure 1 presents a polycrystalline texture with a preferred orientation that changes from (001) for the undoped to (200) for Indium doped Gadolinia thin layers plus those (200) peaks were shifted towards higher angles which it can be caused by the difference in the ionic radius of $\mathrm{Gd}^{3+}(0.938 \AA)$ and $\operatorname{In}^{3+}(0.80 \AA)$. Furthermore, the intensity of the privileged direction (200) decreases with the increase of Indium concentration in the thin films, this reduction can be as a result of the Indium atoms interfering to diminish the nucleation center of $\mathrm{Gd}_{2} \mathrm{O}_{3}$ [19]. Moreover, the highest intensity of this peak is attached to the 2 at \% In leading to a better crystallinity for our $\mathrm{Gd}_{2} \mathrm{O}_{3}$ thin layer. Also, the increase of the doping rate of Indium starting from 4 at $\%$ to 8 at $\%$, we notice that X-ray patterns are a little bit rough compared to the 2 at $\%$ or undoped films.

The lattice constants, a; b; c, were calculated using peak's positioning through monoclinic structure formula:

$$
\frac{1}{d_{h k l}{ }^{2}}=\frac{1}{\sin ^{2}(\beta)} \cdot\left(\frac{h^{2}}{a^{2}}+\frac{\sin ^{2}(\beta) \cdot k^{2}}{b^{2}}+\frac{l^{2}}{c^{2}}-\frac{2 \cdot h \cdot l \cdot \cos (\beta)}{a c}\right.
$$

Where $d_{h k l}$ the inter-plenary distance and h, k, 1 are the miller indices and $\beta=100.182^{\circ}$ which is the angle between the lattice parameter $\mathrm{a}$ and $\mathrm{b}$ and c successively.

The average crystallites size (D) was calculated using the Debye-Scherrer formula [2]:

$$
D=\frac{0.9 * \lambda}{\beta \cdot \cos (\theta)}
$$

The micro strain $(\varepsilon)$ was calculated by the following equation:

$$
\varepsilon=\frac{\cos (\theta) \cdot \beta}{4}
$$

The micro strain $(\varepsilon)$ was calculated Williamson-Hall equation [19] 


$$
\beta \cos (\theta)=\varepsilon(4 \sin (\theta))+\frac{0.9 \lambda}{D}
$$

The dislocation density $(\delta)$ is a parameter that exhibits crystal lattice discontinuity, it was calculated by the equation: a stress " $\varepsilon "$, leading to a disturbance in the crystallite growth kinetics [12].

Finally, by using $\mathrm{Eq} 3$ to determine the strain parameter " $\varepsilon$ " value in our thin layers, we had an observation of an increase in the stain " $\varepsilon$ " as a function of

Table 2. Structural and lattice parameters and micro strain of In doped $\mathrm{Gd}_{2} \mathrm{O}_{3}$ thin films

\begin{tabular}{|c|c|c|c|c|c|c|c|c|c|c|}
\hline $\mathrm{Gd}_{2} \mathrm{O}_{3}:$ In & $\mathbf{d}_{200}(\AA)$ & $\begin{array}{c}2 \theta\left(^{\circ}\right) \\
(200)\end{array}$ & FWHM & $\varepsilon 1^{-3}$ & $\begin{array}{c}\varepsilon 10^{-3} \\
(W-H)\end{array}$ & $\begin{array}{l}\delta 1^{-2} \\
\left(\mathrm{~nm}^{-2}\right)\end{array}$ & $\begin{array}{c}\text { a }(\AA) \\
\text { “(200)" }\end{array}$ & $\begin{array}{c}\text { b (Å) } \\
\text { "(310)" }\end{array}$ & $\begin{array}{c}\text { c }(\AA) \\
\text { “(203)" }\end{array}$ & D (nm) \\
\hline Undoped & - & - & 1.0965 & 4.7661 & 2.75 & 1.890 & $\begin{array}{l}14.129 \\
/(-201)\end{array}$ & 3.57 & 8.848 & 7.2726 \\
\hline 2 at $\%$ & 6.6071 & 13.328 & 1.15851 & 5.0207 & -9.23 & 2.098 & 13.487 & 3.627 & 8.95 & 6.9038 \\
\hline 4 at $\%$ & 6.7118 & 13.286 & 1.23735 & 5.3627 & -13.91 & 2.394 & 13.423 & 3.58 & 7.842 & 6.463 \\
\hline 6 at $\%$ & 6.6386 & 13.259 & 1.27135 & 5.5102 & -13.88 & 2.527 & 13.557 & 3.6 & 7.855 & 6.2906 \\
\hline 8 at $\%$ & 6.6119 & 13.257 & 1.28181 & 5.5555 & -13.22 & 2.568 & 13.558 & 3.79 & 7.814 & 6.2392 \\
\hline
\end{tabular}

$$
\delta=\frac{1}{D^{2}}
$$

Where $\lambda$ the wavelength of the incident X-Ray beam of $\mathrm{Cu} \mathrm{K} \alpha 1.54056 \AA, \beta$ full width at the half maximum (FWHM) of the diffraction line and $\theta$ is the position of the diffraction peak considered.

The microstructural parameters of prepared undoped and indium doped gadolinium oxide " $\mathrm{Gd}_{2} \mathrm{O}_{3}$ " thin layers are illustrated in Table 2.

Firstly, starting with lattice parameters of the monoclinic structure. The JCPDS card number 01-0767419 presents them as follow $a=14.195 \AA, b=3.566 \AA$ and $\mathrm{c}=8.77 \AA$ [9] Through calculations of lattice parameters for our undoped and Indium doped $\mathrm{Gd}_{2} \mathrm{O}_{3}$ thin films, using Equation 1 then presenting the results obtained in Table 2.

Using the monoclinic structure JCPDS card mentioned above as a footing for comparison with lattice parameters calculated and presented in table 2 . We notice, on one hand, that the undoped $\mathrm{Gd}_{2} \mathrm{O}_{3}$ thin film its lattice parameters $(\mathrm{a}, \mathrm{b}, \mathrm{c})$ are slightly different from that of the standard $\mathrm{Gd}_{2} \mathrm{O}_{3}$ monoclinic crystals indicating that our layer of Gadolinia has a very good crystalline structure. On the other hand, the lattice parameters for In doped $\mathrm{Gd}_{2} \mathrm{O}_{3}$ films are inferior to the standard Gadolinia crystals. This reduction can be relate to a substitution of $\mathrm{Gd}^{3+}$ ions having an ionic radius of $(0.938 \AA$ ) with a much smaller one presented in $\operatorname{In}^{3+}(0.80 \AA)$.

Secondly, moving to crystallite size (D) parameter of the $\mathrm{Gd}_{2-\mathrm{x}} \mathrm{In}_{\mathrm{x}} \mathrm{O}_{3}(\mathrm{x}=0,2,4,6$ and 8 at $\%)$ thin films. This parameter (D) is calculated using Eq. 2 and presented in Table 2. By analyzing the results obtained (Tab. 2), we reached a conclusion of that by increasing In dopant concentration the mean crystallite size decreases from $7.2726 \mathrm{~nm}$ for undoped $\mathrm{Gd}_{2} \mathrm{O}_{3}$ : In layer to $6.2392 \mathrm{~nm}$ for $\mathrm{Gd}_{2-0.08} \mathrm{In}_{0.08} \mathrm{O}_{3}\left(8\right.$ at \%) thin layer (Fig. 3). Where $\mathrm{Gd}_{2-}$ ${ }_{0.02} \mathrm{In}_{0.02} \mathrm{O}_{3}(2$ at \%) have the largest grain size between the doped samples and exhibits a better crystallinity compared to the others. So, the decrease of the mean crystallite size of our layers can be explain by the difference in the size of the radius between $\mathrm{Gd}^{3+}$ ions $(0.938 \AA)$ and $\operatorname{In}^{3+}$ ions $(0.80 \AA)$ where it may have caused increasing the In doping concentration as shown in Table 2. This act causes a peak broadening "FWHM" (Table 2) affecting the average crystallite size to decrease (Fig. 2).

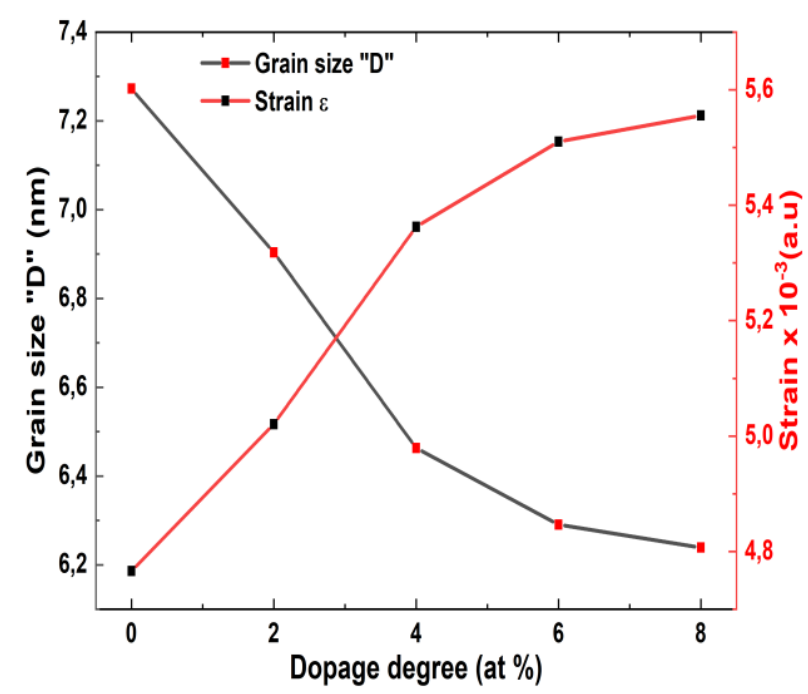

Fig. 2. Average grain size, micro strain as a function of Undoped and In doped $\mathrm{Gd}_{2} \mathrm{O}_{3}$ thin films.

So, to further more understand the nature of the micro strain Eq 4 was used. The Williamson-Hall equation is used to determine the nature and strain value residue into $\mathrm{Gd}_{2-\mathrm{x}} \mathrm{In}_{\mathrm{x}} \mathrm{O}_{3}$ lattice by determining the slope of $(\beta \cos (\theta))$ as a function of $(4 \sin (\theta))$ of different peaks [19]. We've obtained a negative values corresponding to In doped $\mathrm{Gd}_{2} \mathrm{O}_{3}$ layers indicating the presence of a compressive strain in the $\mathrm{Gd}_{2-\mathrm{x}} \mathrm{In}_{\mathrm{x}} \mathrm{O}_{3}$ films caused by the difference in the radius size (Fig. 3), acknowledging the substitution of $\mathrm{Gd}^{3+}$ ions $(0.938 \AA)$ with $\mathrm{In}^{3+}(0.80 . \AA)$ into the lattice. Moreover, we can see that the smallest value of the dislocation density " $\delta$ ", obtained through Eq 5, correspond to 2 at $\%$, with a value of $\delta=2.09810^{-2} \mathrm{~nm}^{-2}$ (Tab. 2), indicating an occurrence of a minimal disturbance to $\mathrm{Gd}_{2} \mathrm{O}_{3}$ lattice. 


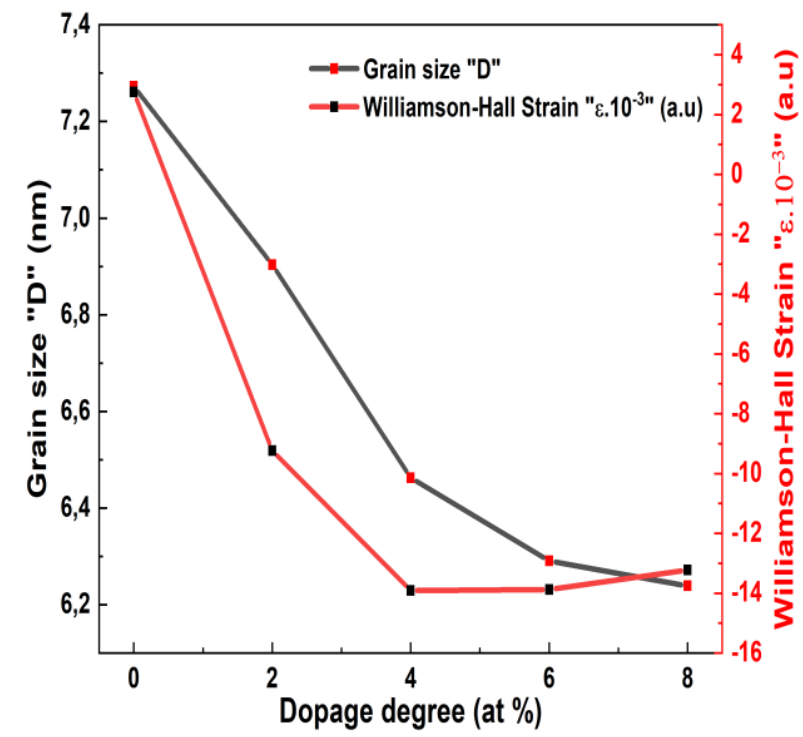

Fig. 3. Average grain size, Williamson-Hall micro strain as a function of Undoped and In doped $\mathrm{Gd}_{2} \mathrm{O}_{3}$ thin films.

\subsection{Raman spectroscopy results}

Raman spectroscopy is a powerful in-situ, nondestructive tool used to investigate the inelastic scattering of light emitted by the target, chemical bonds of the sample, through an analysis to identify the various Raman active vibrational, phonon, modes.

At room temperature, The-Raman experiment was carried out by using $\lambda=532 \mathrm{~nm}$ line of $20 \mathrm{~mW}$ powered laser, where the laser beam was directly focused on undoped and $\mathrm{In}$ doped $\mathrm{Gd}_{2} \mathrm{O}_{3}$ samples through a microscope objective of (x50). The studied Raman Spectrum of $\mathrm{Gd}_{2-\mathrm{x}} \mathrm{In}_{\mathrm{x}} \mathrm{O}_{3}(\mathrm{x}=0,2,4,6$ and 8 at $\%)$ are illustrated in Figure 4 and the obtained frequency are presented in the Table 3.

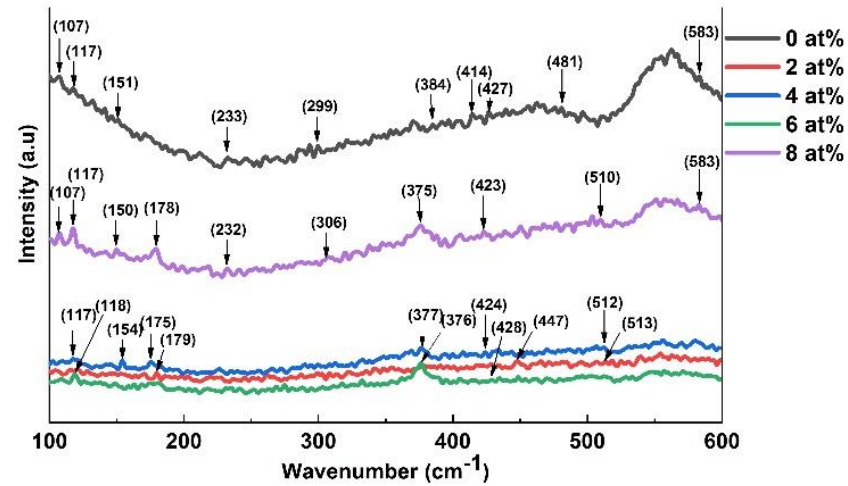

Fig. 4. Raman spectra of Undoped and In doped $\mathrm{Gd}_{2} \mathrm{O}_{3}$ thin films.

Based on the data presented in Table 3 of the microRaman wavenumber $\left(\mathrm{cm}^{-1}\right)$ analysis of the In doped $\mathrm{Gd}_{2} \mathrm{O}_{3}$ samples, we can confirm that the results obtained belongs to the monoclinic B-type structure (space group C $2 / \mathrm{m}$ ) affirming the deduction, $\mathrm{Gd}_{2} \mathrm{O}_{3}$ : In structure, obtained through the $\mathrm{X}$-ray diffraction analysis above.

Based on the factor group analysis, Zarembowitch et al [20] defined the Raman active modes in the monoclinic
$\mathrm{Gd}_{2} \mathrm{O}_{3}$ to be 21 Raman active modes at the center of Brillioune zone. In addition, Paul et al [21] have predicted those modes to be 14 related to $\mathrm{Ag}_{\mathrm{g}}$ modes and 7 of them related to $\mathrm{B}_{\mathrm{g}}$ modes.

Hence, In accordance with other articles [20,21,2], Table 3 and Figure 4, we have identified in the interval of $100-600 \mathrm{~cm}^{-1}, 9$ Raman peaks plus a shoulder at 583 $\mathrm{cm}^{-1}$ for the undoped $\mathrm{Gd}_{2} \mathrm{O}_{3}$ layer then a 4, 6, 3 and a 9 Raman peaks for $\mathrm{Gd}_{2} \mathrm{O}_{3}$ : In (2, 4, 6 and 8 at \%) samples successively. In addition to that, there was an absence of any Raman peaks matching with $\mathrm{In}_{2} \mathrm{O}_{3}$ or any other unwanted impurity phase in our In doped $\mathrm{Gd}_{2} \mathrm{O}_{3}$ samples [22]. Furthermore, we noticed a certain shifting of the Raman peaks in our samples, which can be caused by $\mathrm{In}^{3+}$ ions introduced into Monoclinic $\mathrm{Gd}_{2} \mathrm{O}_{3}$ lattice, where this substitution leads to a change in the chemical band length of our molecule [23]. In one hand, based on Table 3, there was a slight shift of 3 to $5 \mathrm{~cm}^{-1}$ towards the lowest wavenumbers $\left(\mathrm{cm}^{-1}\right)$ concluding the presences of micro strain in $\mathrm{Gd}_{2} \mathrm{O}_{3}$ : In lattice [2]. On the other hand, we noticed a similar shift of the peaks towards the highest wavenumbers $\left(\mathrm{cm}^{-1}\right)$ generated by the reduction of the mean grain size in $\mathrm{Gd}_{2} \mathrm{O}_{3}$ : In thin layers [21]. Finally, those results confirms our results and findings in X-ray diffraction paragraph

Table 3. Obtained data of Raman active modes and assigned Raman active modes of In doped $\mathrm{Gd}_{2} \mathrm{O}_{3}$

\begin{tabular}{|c|c|c|c|c|c|c|}
\hline \multicolumn{5}{|c|}{$\mathbf{G d}_{2} \mathrm{O}_{3}:$ In Obtained } & \multirow{2}{*}{$\begin{array}{c}\text { Mode } \\
\text { assign- } \\
\text { ment } \\
\text { factor } \\
\text { group } \\
{[20]}\end{array}$} & \multirow{2}{*}{$\begin{array}{c}\text { Reported } \\
\text { wave- } \\
\text { number } \\
\left(\mathrm{cm}^{-1}\right)\end{array}$} \\
\hline $\begin{array}{c}0 \\
\text { at } \%\end{array}$ & $\begin{array}{c}2 \\
\text { at\% }\end{array}$ & $\begin{array}{c}4 \\
\text { at } \%\end{array}$ & $\begin{array}{c}6 \\
\text { at } \%\end{array}$ & $\begin{array}{c}8 \\
\text { at\% }\end{array}$ & & \\
\hline 107 & - & - & - & 107 & $\mathrm{Ag}$ & 109 \\
\hline 117 & - & 117 & 118 & 117 & $\mathrm{Bg}$ & 115 \\
\hline 151 & & 154 & - & 150 & $\mathrm{Ag}$ & 150 \\
\hline- & 179 & 175 & - & 178 & $\mathrm{Ag}$ & 176 \\
\hline 233 & - & - & - & 232 & & $233[13]$ \\
\hline 299 & - & - & - & 306 & $\mathrm{Bg}$ & 299 \\
\hline 384 & 376 & 377 & 376 & 375 & $\mathrm{Ag}$ & 385 \\
\hline 414 & - & - & - & - & $\mathrm{Bg}$ & 416 \\
\hline 427 & - & 424 & 428 & 423 & $\mathrm{Bg}$ & 427 \\
\hline- & 447 & - & - & - & $\mathrm{Ag}$ & 442 \\
\hline 481 & & - & - & - & $\mathrm{Ag}$ & 483 \\
\hline & 513 & 512 & - & 510 & & $514[13]$ \\
\hline 583 & - & - & - & 583 & $\mathrm{Ag}$ & $580 \mathrm{sh}$ \\
\hline
\end{tabular}


3.3 Optical and optoelectronic properties of $\mathrm{Gd}_{2} \mathrm{O}_{3}$ : In thin films

The transmittance spectra of the undoped and In doped $\mathrm{Gd}_{2} \mathrm{O}_{3}(2,4,6$ and 8 at \%) thin films, obtained through the UV-Vis-NIR spectrophotometer in a spectra range of 220 to $1600 \mathrm{~nm}$, are presented in Figure 5.

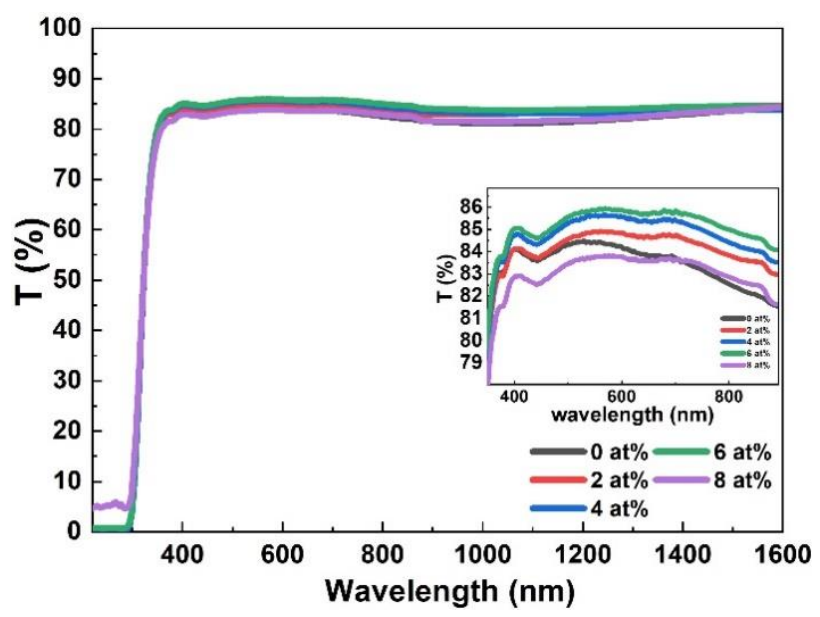

Fig. 5. Transmittance graph of the $\mathrm{Gd}_{2-\mathrm{x}} \mathrm{In}_{\mathrm{x}} \mathrm{O}_{3}(\mathrm{x}=0,2,4,6,8$ at) thin films. Insert; display a zoom in the visible region of the elaborated $\mathrm{Gd}_{2} \mathrm{O}_{3}$ :In thin films.

These illustrations (Fig 5) are done after the subtraction of the transmission of the glass substrates.

To begin, the transmittance value of the undoped gadolinium oxide reaches a round value of $83,46 \%$ in the visible spectra range, $370-900 \mathrm{~nm}$ (figure 5), which agrees with previous research results that have been done placing the transmittance of gadolinium oxide thin film in a range between $70-90 \%$ [2]. Where the variance of the value is dependable on the technics and parameters of elaboration used to obtain the thin films $[2,6]$.

Moreover, slight incrementation in transmittance value was observed as a function of Indium doping in gadolinium oxide, leading to a maxima of $\mathrm{T}=85.243 \%$ for the 6 at $\%$ indium doped. Also, refractive index, n, was calculated using the following equation and presenting it in figure $6[24]$ :

$$
n=\frac{1-R}{1+R}+\left(\frac{4 R}{(1-R)^{2}}-k^{2}\right)^{\frac{1}{2}}
$$

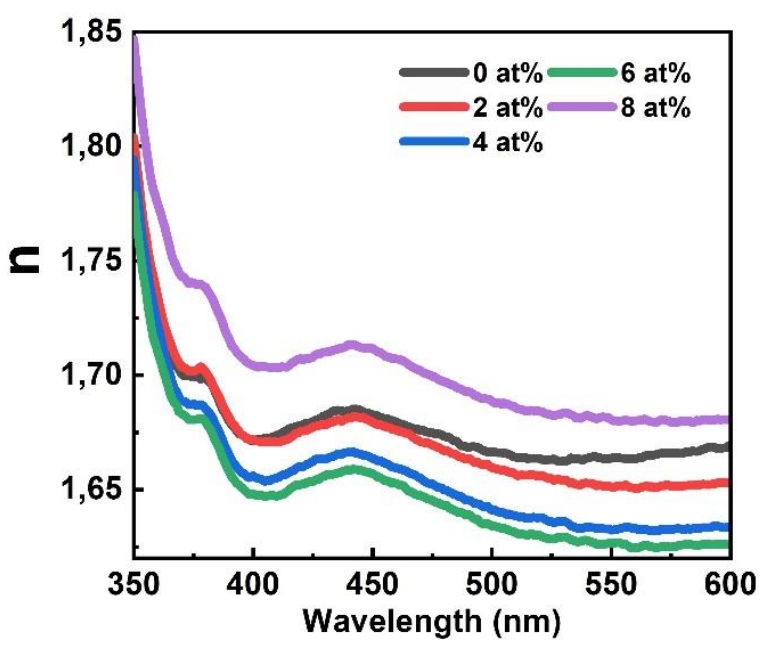

Fig. 6. Refractive index "n" of Undoped and In doped $\mathrm{Gd}_{2} \mathrm{O}_{3}$ thin films.

Where $\mathrm{R}$ is the reflection and $\mathrm{k}$ is the extinction index.

Therefore, the values obtained for our thin films for a wavelength equals to $500 \mathrm{~nm}$ are between 1,666 for undoped gadolinium oxide and 1,688 for the Indium ratio of 8 at $\%$ (Table 4$)$. The result obtained for the undoped gadolinium oxide thin film which is 1,666 is relatable to other research works such as M. Misha et al. [2] that found it in between 1,6 and 1,8 for different temperatures and 1,6 and 1,7 for different oxygen partial pressure, also Q. S. Johnson et al.[10]

In addition, the graphs obtained in figure 7 shows an increase in the absorbance from undoped gadolinium oxide to 2 at then 4 at \% indium doped gadolinium oxide respectively. This increase can be correlated with crystallite average size where the diminution amplify the light interactions with our thin films leading to an augmentation in it [25].

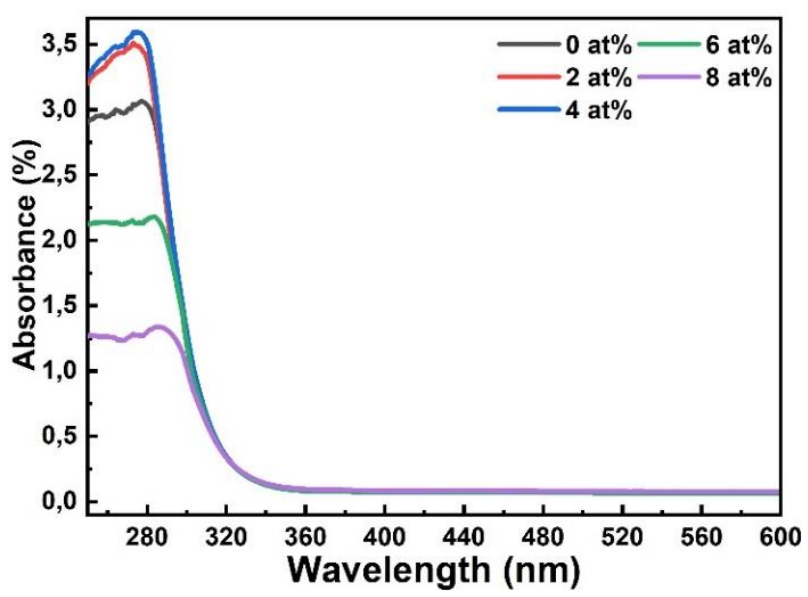

Fig. 7. Absorbance spectra of the $\mathrm{Gd}_{2-\mathrm{x}} \mathrm{In}_{\mathrm{x}} \mathrm{O}_{3}(\mathrm{x}=0,2,4,6,8$ at $\%)$ thin layers deposited on glass.

The band gap energy $E_{\mathrm{g}}$ was estimated through Tauc model relating the photon energy hv and the absorption coefficient $\alpha[6]$ :

$$
\alpha h v=C\left(h v-E_{g}\right)^{r}
$$

Where $\mathrm{C}$ is a constant, $\mathrm{E}_{\mathrm{g}}$ is the gap energy $« \mathrm{eV} »$, hv is phonon energy « $\mathrm{eV} »$ and $\langle\mathrm{r}=1 / 2 »$ for direct band gap. By scanning the entire energy domain The resolution 
of this equation is done graphically by plotting $(\alpha h v)^{2}$ as a function of the energy of a photon $\mathrm{hv}(\mathrm{eV})$ and extrapolating the linear part of $\alpha$ up to the axis of the abscissa $(\alpha=0)$ and finally obtaining $E_{g}$ value [24]. So, the band gap energies of our $\mathrm{Gd}_{2-\mathrm{x}} \mathrm{In}_{\mathrm{x}} \mathrm{O}_{3}(\mathrm{x}=0,2,4,6$ and 8 at $\%$ ) thin films where plotted and presented in figure 8 .

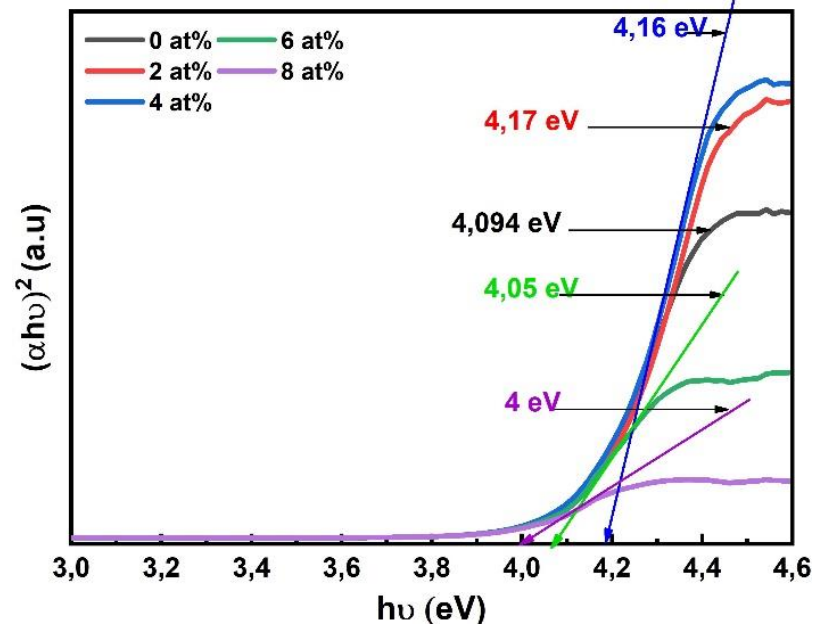

Fig. 8. Gap energy ploted by $(\alpha h v)^{2}$ vs (hv) of the Undoped and In doped $\mathrm{Gd}_{2} \mathrm{O}_{3}$ thin films.

The use of Tauc plot pointed out, the elaborated thin films have a direct band gap, which is in accordance with various reported results [2]. Hence, the band gap value of the elaborated undoped gadolinium oxide thin film is $\mathrm{E}_{\mathrm{g}}=$ $4,09 \mathrm{eV}$, this results is similar to the one obtained by $\mathrm{M}$. Pattabi et al. [17], we note also that band gap value of gadolinium oxide with a monoclinic structure obtained through a DFT calculation is $\mathrm{E}_{\mathrm{g}}=3,8 \mathrm{eV}$ [26]. So, after introducing the dopant element, Indium, at a different concentration rate we notice a blue shift in the band gap value of Indium 2 and 4 at $\%$ at $4,17 \mathrm{eV}$ and $4,16 \mathrm{eV}$ respectively (Fig 8). This increase is related to the augmentation of the carrier electrons introduced, leading to a shift and merge of Fermi level into the covalent band, which is known as Burstein-Moss effect [27]. Concerning the 6 and 8 at \% of Indium doped gadolinium oxide thin films, a red shift is occurring (Fig 8) caused by an emergence of localized energy states within the band gap [28].

Furthermore, to investigate more the absorbance data, we estimated the disorder by Urbach tail using the following equation [18]:

$$
\alpha=\alpha_{0} e^{\left(\frac{h \vartheta}{E_{u}}\right)}
$$

Where $\alpha_{0}$ is a constant, $\mathrm{E}_{\mathrm{u}}$ is the Urbach energy that highlights the intrinsic anomalies of lattice presented in structural disorder and defectiveness, it's determined by the slope of the exponential edge calculated by fitting linear portions of $\ln (\alpha)$ in terms of the photon energy ho then represented in Figure 9. We found that the Urbach energy increases as a function of Indium doping concentration, where it's increases from $\mathrm{E}_{\mathrm{u}}=0,205 \mathrm{eV}$ for the undoped gadolinium oxide thin film to $\mathrm{E}_{\mathrm{u}}=0.239 \mathrm{eV}$ for Indium ratio of 8 at \%. Based on the work of A.F. Zatsepin et al. [29] the increase in the degree of disorder is related with particle size effect, where grains size reduction causes a thrivingness of defectiveness (Grain size, Tab. 2).

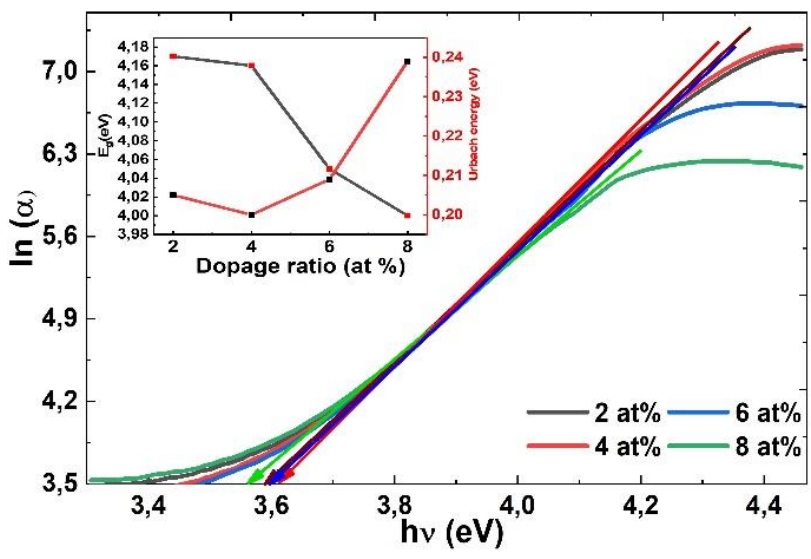

Fig. 9. $\ln (\alpha)$ vs phonon energy $(\mathrm{eV})$ spectra of the $\mathrm{Gd}_{2-\mathrm{x}} \mathrm{In}_{\mathrm{x}} \mathrm{O}_{3}$ $(\mathrm{x}=2,4,6,8$ at $\%)$ thin layers. The insert, the band tail width, $\mathrm{E}_{\mathrm{u}}$ upon the $\mathrm{Gd}_{2-\mathrm{x}} \mathrm{In}_{\mathrm{x}} \mathrm{O}_{3}(\mathrm{x}=2,4,6,8$ at \%) thin films.

Table 4. Optical parameters of $\mathrm{Gd}_{2-\mathrm{x}} \mathrm{In}_{\mathrm{x}} \mathrm{O}_{3}(\mathrm{x}=0,2,4,6$ and 8 at $\%)$ thin films

\begin{tabular}{|c|c|c|c|c|}
\hline $\mathrm{Gd}_{2} \mathrm{O}_{3}:$ In & $\begin{array}{l}\text { Average } \\
\text { T }(\%) \text { in } \\
\text { the }[370- \\
900 \mathrm{~nm}]\end{array}$ & $\begin{array}{c}\mathbf{E g}_{\mathrm{g}} \\
(\mathrm{eV})\end{array}$ & $\begin{array}{c}\mathbf{E}_{\mathbf{u}} \\
(\mathrm{eV})\end{array}$ & $\begin{array}{c}\text { Refractive } \\
\text { index, } n\end{array}$ \\
\hline Undoped & 83,46 & 4,09 & 0,205 & 1,666 \\
\hline 2 at $\%$ & 84,208 & 4,17 & 0,205 & 1,659 \\
\hline 4 at $\%$ & 84,856 & 4,16 & 0,200 & 1,641 \\
\hline 6 at $\%$ & 85,243 & 4,05 & 0,209 & 1,634 \\
\hline 8 at $\%$ & 83,11 & 4 & 0,239 & 1,688 \\
\hline
\end{tabular}

\section{Conclusion}

To conclude, a good quality of undoped and Indium doped $\mathrm{Gd}_{2} \mathrm{O}_{3}(0,2,4,6$ and 8 at \%) thin layers have been elaborated on a glass substrate using a homemade Spray pyrolysis technic. A number of properties where investigated using both characterization technics and semiempirical equations to determine the structural, morphological and optical properties.

The structural properties show a well crystallize Monoclinic B-type structure for all the thin films elaborated $\mathrm{Gd}_{2} \mathrm{O}_{3}$ : In $(0,2,4,6$ and 8 at \%) with a change in the preferential orientation from $\left(\begin{array}{lll}0 & 0 & 1\end{array}\right)$ for the undoped $\mathrm{Gd}_{2} \mathrm{O}_{3}$ to $\left(\begin{array}{lll}0 & 0 & 2\end{array}\right)$ orientation for the In doped $\mathrm{Gd}_{2} \mathrm{O}_{3}$ layers. Furthermore, the Raman spectroscopy support the X-ray diffraction results obtained. Concerning the optical properties, Indium ratio of 2 at $\%$ presents a good transmittance in the visible range $(84,208 \%)$ with a band gap equals to $4,17 \mathrm{eV}$ allowing him to absorbance a certain short wave in the UV and also a good refractive index $(1,659)$. This improvement of parameters may push it to be used as an optical window for solar cells. 


\section{Reference}

[1] G. Niu, B. Vilquin, N. Baboux, C. Plossu, L. Becerra, G. Saint-Grions, G. Hollinger," Growth temperature dependence of epitaxial $\mathrm{Gd}_{2} \mathrm{O}_{3}$ films on $\mathrm{Si}(111)$ ", Microelectronic Engineering, vol. 86, pp. 1700-1702, (2009)

[2] M. Mishra, P. Kuppusami, S. Ramya, V. Ganesan, A. Singh, R. Thirumurugesan, E. Mohandas," Microstructure and optical properties of $\mathrm{Gd} 2 \mathrm{O} 3$ thin films prepared by pulsed laser deposition", Surface \& Coatings Technology, vol. 262, pp. 56-63, (2015)

[3] J.S. Revathy and D.N. Rajendran," Temperature dependent photoluminescence studies of NUV excited $\mathrm{Gd}_{2} \mathrm{O}_{3}$ : Eu phosphor", Materials Today: Proceedings, vol. 47, pp. 2007-2012, (2021)

[4] P. Gribisch, A. Roy Chaudhuri, A. Fissel, "Growth and dielectric properties of monoclinic $\mathrm{Gd}_{2} \mathrm{O}_{3}$ on Si(111)", ECS Transactions, vol. 93 (1), pp. 57-60, (2019)

[5] N.K. Sahoo, S. Thakur, M. Senthilkumar, D. Bhattacharyya, N.C. Das,“ Reactive electron beam evaporation of gadolinium oxide optical thin films for ultraviolet and deep ultraviolet laser wavelengths", Thin Solid Films, vol. 440, pp. 155-168, (2003)

[6] M. P. Singh, C.S. Thakur, K. Shalini, S. Banerjee, N. Bhat, S. A. Shivashankar," Structural, optical, and electrical characterization of gadolinium oxide films deposited by low-pressure metalorganic chemical vapour deposition", Journal of Applied Physics, vol. 96 (10), pp. 5631-5637, (2004); doi:10.1063/1.1801157

[7] R.A.S. Ferreira et al.," Spectral converters for photovoltaics - what's ahead", Materials Today, vol. 33, pp. 105-121, (2020), doi:10.1016/j.mattod.2019.10.002

[8] N. L. Michel, D. L. Flores and G. A. Hirata," Magnetic-luminescent spherical particles synthesized by ultrasonic spray pyrolysis", Materials Research Express, vol. $\quad 2$, (2015) 076103, doi:10.1088/2053$1591 / 2 / 7 / 076103$

[9] L. Laversenne, Y. Guyot, C. Goutaudier, M. Th. Cohen-Adad, G. Boulon," Optimization of spectroscopic properties of $\mathrm{Yb}^{3+}$-doped refractory sesquioxides: cubic $\mathrm{Y}_{2} \mathrm{O}_{3}, \mathrm{Lu}_{2} \mathrm{O}_{3}$ and monoclinic $\mathrm{Gd}_{2} \mathrm{O}_{3}{ }^{\text {", }}$, Optical Materials, vol.16, pp. 475-483, (2001)

[10] Q. S. Johnson, M. Edwards, M. Curley," Analysis of the refractive index and film thickness of $\mathrm{Eu}$ doped gadolinium oxide $\left(\mathrm{Gd}_{2} \mathrm{O}_{3}\right)$ planar waveguides fabricated by the sol-gel and dip coating methods", Proceedings of SPIE, vol. 8847, (2013), doi:10.1117/12.2023428

[11] B. Lee, H. Jeong, S. Byeon," Layer-by-layer depositon of highly transparent multifunctional $\mathrm{Gd}_{2} \mathrm{O}_{3}: \mathrm{RE} / \mathrm{SiO}_{2}(\mathrm{RE}=\mathrm{Eu}$ and $\mathrm{Tb})$ films, European Journal of Inorganic Chemistry, vol.3298, pp. 3298-3304, (2014), doi:10.1002/ejic. 201400018

[12] M. H. M. Abdelrehman, R. E. Kroon, A. Yousif, H. A. A. Seed Ahmed, H. C. Swart," Photoluminescence, thermoluminescence, and cathodoluminescence of optimized cubic Gd2O3:Bi phosphor powder", J. Vac.
Sci. Technol. A, vol. 38 (6), 063207, (2020); doi.org/10.1116/6.0000567

[13] C. Le Luyer, A. Garcia-Murillo, E. Bernstein, J. Mugnier," Waveguide Raman spectroscopy of sol-gel $\mathrm{Gd}_{2} \mathrm{O}_{3}$ thin films", J. Raman Spectrosc., vol. 34, pp. 234239, (2003), doi:10.1002/jrs.980

[14] N. Paul, D. Mohanta," Evaluation of optoelectronic response and raman active modes in $\mathrm{Tb}^{3+}$ and $\mathrm{Eu}^{3}{ }_{+}$-doped gadolinium oxide $\left(\mathrm{Gd}_{2} \mathrm{O}_{3}\right)$ nanoparticules systems",Appl. Phys. A, vol. 122 (9), (2016), doi:10.1007/s00339-0160347-6

[15] X. Wang, A. Laha, A. Fissel, D. Schwendt, R. Dargis, T. Watahiki, R. Shayduk,W. Braun, T. M. Liu, H. J. Osten," Crystal structure and strain state of molecular beam epitaxial grown $\mathrm{Gd}_{2} \mathrm{O}_{3}$ on $\mathrm{Si}(111)$ substrates: a diffraction study", Semicond. Sci. Technol., vol. 24 (4), 045021, (2009), doi:10.1088/0268-1242/24/4/045021

[16] J. Niinisto, N. Petrova, M. Putkonen, L. Niinisto, K. Arstila, T. Sajavaara," Gadolinium oxide thin films by atomic layer deposition", Journal of Crystal Growth, vol. 285, pp. 191-200, (2005), doi:10.1016/j.jcrysgro.2005.08.002

[17] M. Pattabi, G. A. K. Thilipan," Preparation and characterization of Gd2O3 thin films by RF Magnetron Sputtering", AIP Conf. Proc., vol. 1512, pp. 726-727, (2013), doi: 10.1063/1.4791243

[18] H. Ftouhi, Z. El Jouad, M. Jbilou, M. Diani, M. Addou," Study of microstructural, morphological and optical properties of sprayed vanadium doped $\mathrm{ZnO}$ nanoparticules", The European Physical Journal Applied Physics, vol. 87(1), 10301, (2019), doi:10.1051/epjap/2019190111

[19] A. Adjimi, M. S. Aida, N. Attaf and Y. S. Ocak,"Gadolinium doping effect on $\mathrm{SnO} 2$ thin films optical and electrical properties", Materials Research Express, vol.6, (2019) 096405

[20] J. Zarembowitch, J. Gouteron and A. M. Lejus," Raman spectrum of single crystals of monoclinic B-type gadolinium sesquioxide", JOURNAL OF RAMAN SPECTROSCOPY, vol. 9 (4), (1980)

[21] N. Paul, M. Devi, D. Mohanta," Synthesis, characterization and effect of low energy Ar ion Irradiation on gadolinium oxide nanoparticles", Materials Research Bulletin, vol. 46, pp. 1296-1300, (2011)

[22] K. Yadav, B. R. Mehta, J. P. Singh,'Template-free synthesis of vertically aligned crystalline indium oxide nanotube arrays by pulsed argon flow in a tube-in-tube chemical vapour depositon system", Journal Materials Chemistry $C$, vol. 2(31), pp. 6362-6369,(2014), doi:10.1039/c4tc00491d

[23] B. J. Sarkar,a A. K. Debb, P. K. Chakrabarti,” XRD, HRTEM,Raman and magnetic studies on chemically prepared nanocrystalline Fe-doped gadolinium oxide $(\mathrm{Gd} 1.9 \mathrm{Fe} 0.1 \mathrm{O} 3-\delta)$ annealed in vacuum", $R S C$ Advances,vol. 6(8), 6395-6484, (2016) doi: $10.1039 / \mathrm{c} 5 \mathrm{ra} 22867 \mathrm{k}$

[24] A. El Haimeur, Z. Zarhri, M. Bouaouda, J. Colin, M. Addou, A. Elkenz," Synthesis, structural, optical and 
magnetic properties in the sprayed $\mathrm{ZnO}: \mathrm{Fe}^{3+}$ : explanations of the origin of the tuned ferromagnetism and optical parameters by first principle", Materials Research Express, vol. 5(7), (2018), doi:10.1088/20531591/aad11c

[25] A. El Haimeur, Z. Zarhri, L. El Gana, J. Zimou, M. Addou, J. Colin, A. El Kenz," Structural, electronic, magnetic, optical and optoelectronic properties of the sprayed cobalt doped $\mathrm{ZnO}$ nanostructured thin films", Materials Research Express, (2018), doi: 10.1088/20531591/aad123

[26] Y. B Losovyj, D. Wooten, J. C. Santana, J. M. An, K. D. Belashchenko, Lozova, J. Petrosky, A. Sokolov, J. Tang, W. Wang, N. Arulsamy, P. A. Dowben," Comparison of n-type $\mathrm{Gd}_{2} \mathrm{O}_{3}$ and Gd-doped $\mathrm{HfO}_{2}$ ", Journal of Physics: Condensed Matter, vol. 21(4), (2009), doi:10.1088/0953-8984/21/4/045602

[27] A. Klein, C. Korber, A. Wachau, F. Sauberlich, Y. Gassenbauer, S. P. Harvey, D. E. Proffit and T. O. Mason," Transparent conducting oxides for photovoltaics:Manipulation of Fermi level, work function and energy band alignement", Materials, vol. 3(11), pp. 4892-4914, (2010); doi:10.3390/ma3114892

[28] A. Kumar, C. S. Prajapati, P.P. Sahay," Results on the microstructural, optical and electronic properties of spray-deposited MoO3 thin films by the influence of $\mathrm{W}$ doping", Materials Science in Semiconductor Processing, vol. 104, (2019), doi:10.1016/j.mssp.2019.104668

[29] A. F. Zatsepin \& Yu. A. Kuznetsova, V. N. Rychkov, V. I. Sokolov,"Characteristic features of optical absorption for $\mathrm{Gd}_{2} \mathrm{O}_{3}$ and $\mathrm{NiO}$ nanoparticules", Journal Nanoparticle Research, vol. 19(3), (2017), doi: 10.1007/s11051-017-3821-y 